\title{
Deep burial as a refuge for lady crabs Ovalipes ocellatus: comparisons with blue crabs Callinectes sapidus
}

\author{
Diana E. Barshaw*, Kenneth W. Able \\ Rutgers University Marine Field Station, Great Bay Boulevard, Tuckerton, New Jersey 08087, USA
}

\begin{abstract}
Lady crabs Ovalipes ocellatus use a reversed gill current for respiration. Our evidence suggests that this adaptation allows small lady crabs to use deep burial in high energy sand habitats as a refuge from predation unavailable to other species of crabs. In laboratory experiments lady crabs buried deeper into sand than blue crabs Callinectes sapidus, and such burial was shown to protect lady crabs from predation by larger blue crabs. In field experiments lady crabs and blue crabs were tethered and placed in sand and macroalgae (UIva lactuca)/mud habitats. In the sand habitat more of the small lady crabs survived than the small blue crabs. There was no difference in survival between large crabs of the 2 species. In a macroalgae/mud habitat there were no differences in survival between size classes of crabs or between the 2 species of crabs. These data help to explain the distribution of these crabs.
\end{abstract}

\section{INTRODUCTION}

Lady crabs Ovalipes ocellatus (Portunidae), one of the dominant decapods along the eastern coast of the United States (Epifanio 1988, Dittel \& Epifanio 1982, Stehlik et al. unpubl.), range from Canada to Georgia (Williams 1984). The common habitats of these crabs are sandy beaches (Pearse et al. 1942, Leber 1982). They are also found in the high salinity portions of estuaries and over the continental shelf to depths of $100 \mathrm{~m}$ (Stehlik et al. unpubl.). Members of the genus Ovalipes are major predators of bivalves (O. stephensoni: Haefner 1985; O. catharus: Davidson 1986, Haddon et al. 1987). On the other hand the genus is an important prey item for other crabs and many species of fish including summer flounder, black seabass, striped bass, and Atlantic croaker (Stehlik et al, unpubl.). Despite the abundance of lady crabs and the important role they play in coastal ecosystems, there have been few ecological studies on this genus. In the following 3 experiments we investigated the burial depth and susceptibility of lady crabs to predation in the laboratory

- Present address: Center for Maritime Studies, University of Haifa, Haifa 31999, Israel and the field relative to the sympatric portunid Callinectes sapidus (blue crab).

\section{METHODS AND MATERIALS}

The crabs used in all 3 experiments were collected by trawling and seining in Great Bay, New Jersey, USA. Blue crabs and lady crabs were held separately in tanks with ambient running seawater and fed fish daily. Prior to each experiment all crabs were examined to ensure that they had all their appendages and were intermolt.

Burial depth. Sand collected from a high energy sand bar in Great Bay was placed to a depth of $15 \mathrm{~cm}$ in a plastic tray ( $60 \mathrm{~cm}$ long, $40 \mathrm{~cm}$ wide, $25 \mathrm{~cm}$ deep) and submerged in a seawater table with flowing, ambient $\left(14\right.$ to $25^{\circ} \mathrm{C}$ ) seawater for $24 \mathrm{~h}$. Individual crabs of both species were randomly selected, measured with calipers to determine carapace width (CW; 15 to $35 \mathrm{~mm}$ ), and placed into the tray. If a crab buried before $5 \mathrm{~min}$ had elapsed, the time until burial was recorded and the depth of the crab in the substrate was determined at the anterior (minimum depth) and posterior (maximum depth) portion of the carapace using a stiff piece of wire calibrated in millimeters. The minimum and maximum depth to which each crab was buried was averaged for 
the statistical comparison of burial depth between the 2 crab species in the 2 substrates. If a crab did not bury within $5 \mathrm{~min}$ it was removed, and recorded as no burial'. This procedure was repeated using mud collected from a flat in Great Bay. A total of 16 lady crabs and 15 blue crabs were measured in sand and 14 of both species were measured in mud.

Laboratory predation. Thirty-two replicate tanks $(0.6 \mathrm{~m}$ wide, $0.8 \mathrm{~m}$ long, $0.6 \mathrm{~m}$ deep) were supplied with flowing, ambient ( 24 to $27^{\circ} \mathrm{C}$ ) seawater. In half of the tanks at least $12 \mathrm{~cm}$ of sieved sand collected from the same bar as for the previous experiment was introduced and allowed to stand for $24 \mathrm{~h}$. The remaining 16 tanks had no substrate. Five juvenile lady crabs (12 to $35 \mathrm{~mm} \mathrm{CW}$ ) were placed into each of the tanks to acclimate. After $24 \mathrm{~h}, 2$ blue crabs (41 to $70 \mathrm{~mm} \mathrm{CW}$ ) were placed into half (8) of the sand tanks and half (8) of the tanks with no substrate. The remaining 16 tanks served as predator-free controls. After a further $24 \mathrm{~h}$ the blue crabs were removed and the surviving lady crabs were counted and re-measured.

Field predation. Blue crabs and lady crabs are of dissimilar shape so wet weight was used as the basis for comparing crab size. The crabs were tethered using techniques similar to those used by Heck \& Thoman (1981) and Wilson et al. (1987). Briefly, $1 \mathrm{~m}$ monofilament line was either tied around the width of the lady crabs or tied in a figure-eight around the lateral spines of the blue crabs. The knot was then secured to the carapace with 'Super' glue (cyanoacrylate). The other end of the line was tied to a ' $J$ '-shaped wire which was pushed completely into the substrate. The crabs were placed in subtidal areas at low tide and were recovered $24 \mathrm{~h}$ later $( \pm 2 \mathrm{~h}$ ). After retrieval only tethers on which a piece of carapace still remained were scored as predation events. Crabs which had molted were rare, and easy to discern because their entire carapace remained on the tether. Preliminary observations showed that the crabs were able to bury, feed, and behave normally while tethered.

The tethered crabs were placed in 2 habitats both of which were representative of the generai study area. The first was a sand bar in Great Bay where lady crabs of all sizes were abundant, but blue crabs (usually larger then $150 \mathrm{~mm}$ (W) were only occasionally observed. The second site was located in the mouth of a marsh creek where the mud substrate was covered by the macroalgae Ulva lactuca. Both species of crab were common in this habitat, but lady crabs occurred in smaller numbers than blue crabs.

A total of 172 lady crabs and 129 blue crabs were tethered in 8 trials during 5 to 22 October 1987. Water temperature and salinity were similar at the 2 sites, ranging from 14 to $19^{\circ} \mathrm{C}$ and 28 to $32 \%$.

\section{RESULTS}

\section{Burial depth}

Lady crabs buried significantly deeper then blue crabs in both sand and mud (1-way ANOVA (1WA), Newman-Keuls Test (NKT), p <0.01; Fig. 1A). Lady crabs buried deeper in sand then in mud (1WA, NKT, p $<0.001$ ), but there was no significant difference in how deep blue crabs buried in the 2 substrates.
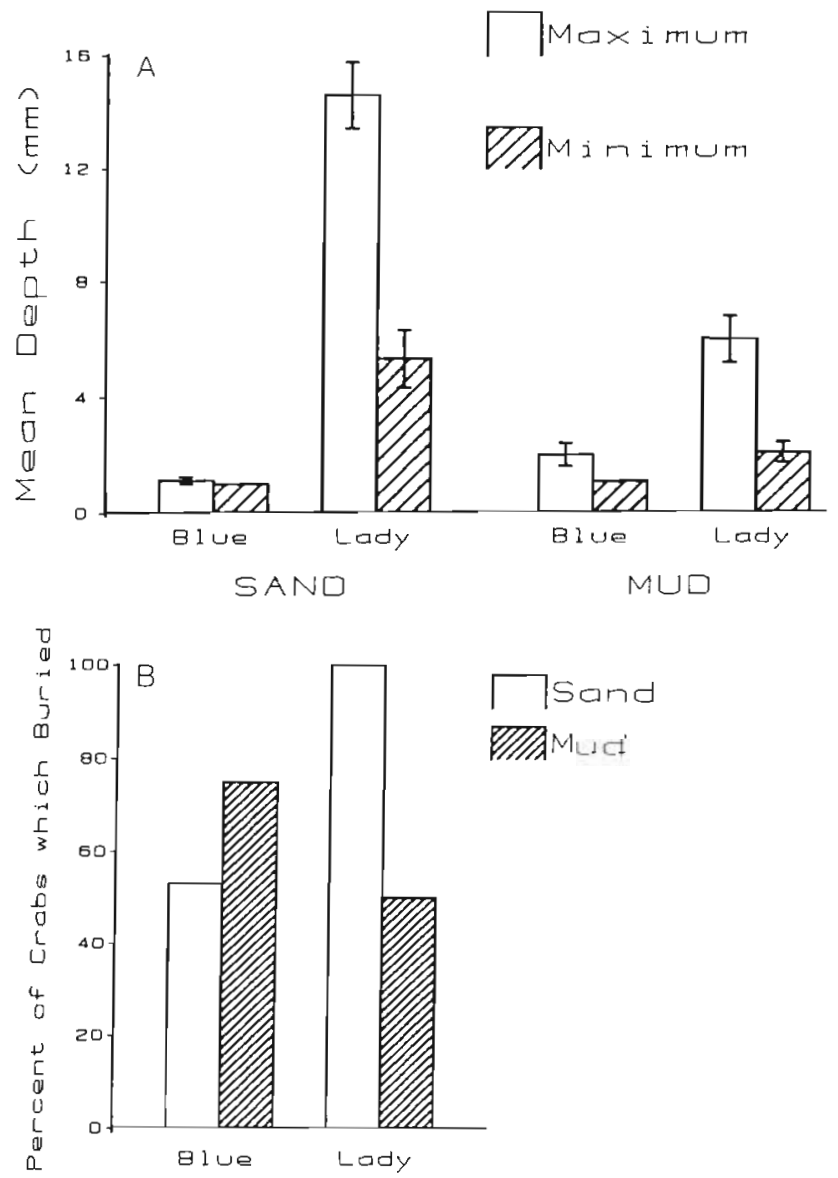

Fig. 1 Ovalipes ocellatus and Callinectes sapidus. (A) Depth to which lady crabs and blue crabs buried in sand and mud. Maximum: depth at posterior portion of carapace; minimum: depth at anterior portion of carapace. (B) Percent of crabs which buried within $5 \mathrm{~min}$ in sand and mud

A significantly greater percent of the lady crabs buried within 5 min in sand than in mud $\left(x^{2}, p<0.01\right)$, while there was no significant difference between percentages of blue crabs that buried in sand versus mud (Fig. 1B). Lady crabs buried at an angle - the posterior portion of their body always deeper then the anterior while blue crabs were horizontal. 
Fig. 2. Ovalipes ocellatus. Carapace width distribution before and those surviving after being preyed upon by Callinectes sapidus
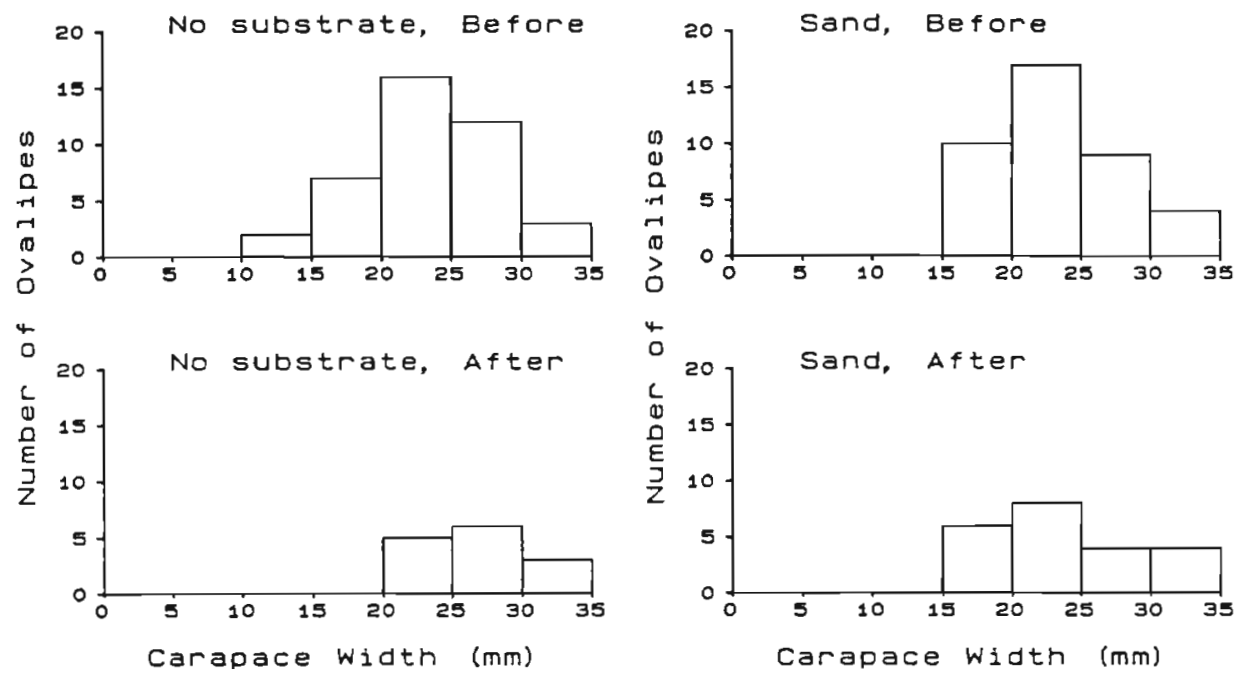

\section{Laboratory predation}

Burial in sand protected lady crabs from being preyed upon by blue crabs. There was no significant difference in survival between the sand control and the no-substrate control, so these data were combined. A significantly greater percent of lady crabs survived in the predator-free controls $(97 \%)$ than in the sand treatment with blue crab predators $(63 \%)$, and there was significantly greater survival in sand than in the nosubstrate treatment $(35 \%)\left(\chi^{2}, p<0.001\right)$. Blue crabs preyed preferentially on the smaller lady crabs. This preference was significant for the no-substrate treatment (Students t-test, $\mathrm{p}<0.05$ ), but was only a trend in the sand treatment (Fig. 2).
Fig. 3. Ovalipes ocellatus and Callinectes sapidus. Percent survival of 2 size classes of lady crabs and blue crabs after being tethered in 2 habitats in the field for $24 \mathrm{~h}$

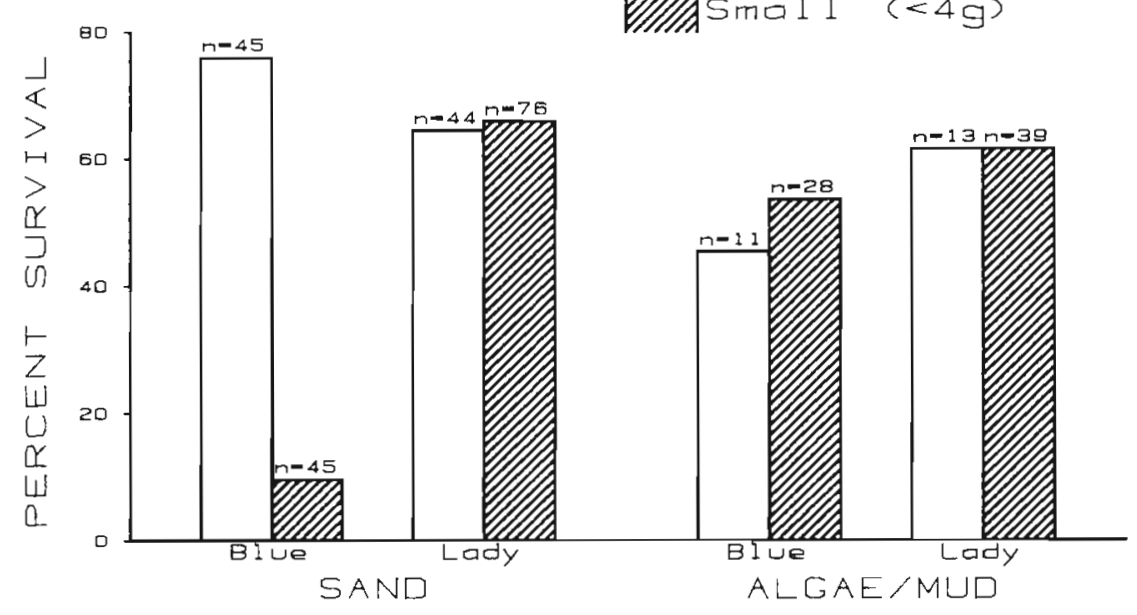

Lady crabs from 1 to $4 \mathrm{~g}$ (18 to $29 \mathrm{~mm} \mathrm{CW}$ ) were less vulnerable to predation on the sand bar than were blue crabs (23 to $36 \mathrm{~mm} \mathrm{CW}$ ) of the same weight $\left(\chi^{2}, \mathrm{p}\right.$ $<0.001$ ). While lady crabs survived at about the same rate independent of their size or of the 2 habitats, survival of the small blue crabs was significantly lower than of either larger blue crabs in the same habitat or any size of crabs in the macroalgae covered mud habitat ( $\chi^{2}, p<0.001$; Fig. 3).
\Large $(>4 g)$

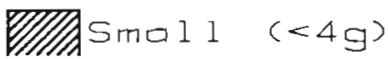




\section{DISCUSSION}

The interaction between burial depth and substrate provides important insights into the distribution and abundance patterns for these 2 portunid crabs. In the laboratory, lady crabs buried deeper than blue crabs, agreeing with the assumption of previous investigators that Ovalipes spp. would be able to bury more deeply than other crabs because they have a reversed gill current (Pearse et al. 1942, Caine 1974, Taylor 1984, Mickay \& Osborne 1985). It was also clear that lady crabs preferred the sand as they buried both deeper and more readily into it than into mud (Fig. 1A, B). In contrast blue crabs tended to bury more readily into mud than sand. These substrate-specific behavior patterns are consistent with the distribution patterns of these 2 species. Lady crabs are more abundant over sand substrate near the Great Bay inlet to the Atlantic Ocean and blue crabs more abundant over mud bottom, based on 14 mo trawl surveys during the period of this study (K. W. Able \& S. T. Szedlmayer pers, obs.).

The orientation of the 2 species when buried is con sistent with their respective methods of respiration. Lady crabs, which have a reversed gill current, always buried with the anterior portion of their body closer to the surface of the substrate thus keeping the intake of the respiratory current in close contact to the water. Blue crabs take in water from the posterior portion of their body, anterolateral to the 5th walking leg (Williams 1984). By burying horizontally they also kept the water intake nearer the surface.

In the laboratory we showed that burial in sand protects lady crabs from predation even by a predator capable of digging. The blue crabs took smaller lady crabs preferentially to larger ones in the no-substrate treatment, while in sand this preference was not significant. In the field there were no significant differences in the amount of predation upon lady crabs with size. Perhaps, by being buried in sand, the disadvantage of being small was ameliorated.

The most dramatic result from the field predation experiment was the lower survival rate of small blue crabs compared to small lady crabs when tethered in the sand habitat (Fig. 3). This result supports the theory that the lady crabs' adaptation to bury deeply in sand allows them to utilize this habitat by protecting them from predation. Depth of burial as a refuge from predation has also been demonstrated for bivalves (Haddon et al. 1987). However, there was no significant difference between survival of large blue crabs and that of large lady crabs.

It is important to consider how the artifact of tethering crabs might affect each species differently (Barshaw \& Able 1990). For example, blue crabs in our first experiment were shown to bury less frequently in sand than did lady crabs. If blue crabs more effectively flee a predator than lady crabs, the tether would bias the results against survival of blue crabs and result in an underestimation of their survival. However, Heck \& Wilson (1987) found no difference in predation rates of tethered crab species that tend to flee versus those that are less mobile and use crypsis as a primary defence.

There were no significant differences between survival of lady crabs and blue crabs of either size class in the macroalgae/mud habitat. Small blue crabs had a significantly higher survival in this habitat than in the sand. While lady crabs might specialize in sand they were shown in these experiments to survive equally well in the mud habitat. Both of these crab species were abundant in mud, supporting the result of equally high survival. Wilson et al. (unpubl.) and our observations indicate that both of these crab species usually do not bury in the mud in these habitats, but instead hide in the Ulva.

In summary, the reversal of the respiratory current of Ovalipes ocellatus allows them to find refuge in a substrate where small individuals of a sympatric portunid crab are susceptible to predation.

Acknowledgements. We thank Donald Bryant-Rich for help in the laboratory and field and Kim Wilson for assistance with the tethering technique. Kari Lavalli commented on an earlier draft. Many personnel at the Rutgers Marine Field Station helped to collect the crabs used in this study. Financial support for this research was provided by the Center for Coastal and Environmental Studies, Rutgers University. This is CCES contribution no. 90-16.

\section{LITERATURE CITED}

Barshaw, D. E., Able, K. W (1990). Tethering as a technique for assessing predation rates in different habitats: an evaluation using juvenile lobsters, Homarus americanus. Fish. Bull. U.S. 88: 415-417

Caine, E. A. (1974). Feeding of Ovalipes quadulpensis (Saussure) (Decapoda: Brachyura: Portunidae), and morphological adaptations to a burrowing existence. Biol. Bull. mar biol. Lab., Woods Hole 147: 550-559

Davidson, R. J. (1986). Mussel selection by the paddle crab Ovalipes catharus (White): evidence of flexible foraging behavior. J. exp. mar. Biol. Ecol. 102: 281-299

Dittel, A. I., Epifanio, C. E. (1982). Seasonal abundance and vertical distribution of crab larvae in Delaware Bay. Estuaries 5 (3): 197-202

Epifanio, C. E. (1988). Dispersal strategies of two species of swimming crab on the continental shelf adjacent to Delaware Bay. Mar Ecol. Prog. Ser. 49: 243-248

Haddon, M., Wear, R. G., Packer, H. A. (1987). Depth and density of burial by the bivalve Paphies ventricosa as refuges from predation by the crab Ovalipes catharus. Mar. Biol. 94: 25-30

Haefner, P. A., Jr (1985). Morphometry, reproduction, diet, and epizoites of Ovalipes stephensoni Williams, 1976 (Decapoda, Brachyura). J. crust. Biol. 5 (4): 658-672

Heck, K. L., Jr, Thoman, T A. (1981). Experiments on preda- 
tor-prey interactions in vegetated aquatic habitats. J. exp. mar. Biol. Ecol. 53: 125-134

Heck, K. L., Jr, Wilson, K. A. (1987). Predation rates on decapod crustaceans in latitudinally separated seagrass communities: a study of spatial and temporal variation using tethering techniques. J. exp. mar. Biol. Ecol. 107: $87-100$

Leber, K. M. (1982). Seasonality of macroinvertebrates on a temperate, high wave energy sandy beach. Bull. mar. Sci. 32 (1): $86-98$

McKay, C. L., Osborne, T. A. (1985). Burrowing behavior of the paddle crab Ovalipes catharus (White 1843) (Brachyura: Portunidae). N. Z. Jl. mar. Freshwat. Res. 19: 125-130

This article was presented by Dr R. S. Scheltema, Woods Hole, Massachusetts, USA
Pearse, A. S., Humm, H. T., Wharton, G. W. (1942). Ecology of sand beaches at Beaufort, N. C. Ecol. Monogr. 12: 135-190

Taylor, A. C. (1984). Branchial ventilation in the burrowing crab, Atelecyclus rotundatus. J. mar. biol. Ass. U.K. 64 : $7-20$

Williams, A. B. (1984). Shrimps, lobsters and crabs of the Atlantic coast of the eastern United States, Maine to Florida. Smithson. Inst. Press, Washington, D.C.

Wilson, K. A., Heck, K. L. Jr, Able, K. W. (1987). Juvenile blue crab, Callinectes sapidus, survival: an evaluation of eelgrass, Zostera marina, as refuge. Fish. Bull. U.S. 85 (1): $53-58$

Manuscript first received: October 9, 1989 Revised version accepted: March 12, 1990 